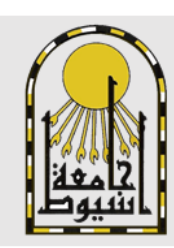

Journal of

Engineering Sciences

Faculty of Engineering

Assiut University

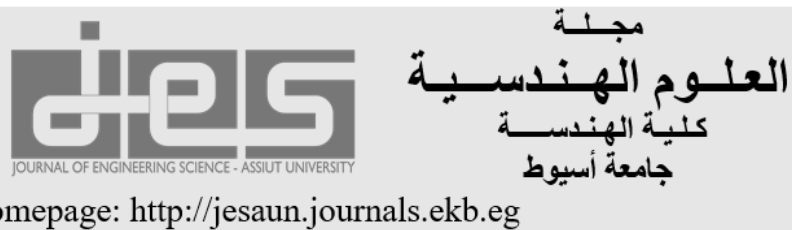

journal homepage: http://jesaun.journals.ekb.eg

\title{
A Simultaneous System Model to Estimate Temperature of Pavement Layers: Development and Validation
}

Talaat Abdel-Wahed ${ }^{1}$ Mohamed El Esawey ${ }^{2}$ Sherif. A. Mohamed ${ }^{3}$

\section{Keywords}

Flexile pavement; Surface Temperature; Radiation Heat Flux; Thermal Layers Properties; Weather Conditions.

\begin{abstract}
Many roads in hot regions of the world are exposed to very high temperatures especially in desert areas during the summer season, where the temperature could reach more than sixty Celsius degrees. Temperature variations cause a lot of distress in flexible and rigid pavement such as rutting, vertical transverse (i.e., thermal) cracking, thermal fatigue damage, blow up/buckling, in addition to generating warping stresses. Accurate detection of the surface temperature of flexible pavement is very important for pavement design analysis. This research presents a new model to estimate the temperature of flexible pavement layers under extremely high temperatures as a set of simultaneous equations. The proposed model included Clear-Sky as sub-model to estimate the solar energy of beam and diffuse radiation of the pavement surface. Ambient temperature was calculated by solving the model depending on the time of the day. The proposed model was validated via experimental data collected from one-year measurements at instrumented pavement section in New Sohag, Egypt. The asphalt surface temperatures were measured for summer, winter solstices and vernal and autumnal equinoxes. It was found that the model provides reasonable estimates compared to the experimental data. The proposed model is deemed appropriate for estimating pavement layers temperature in hot regions.
\end{abstract}

\section{Introduction}

Pavement performance is substantially impacted by traffic loads and pavement temperature $[1,2]$. Reliable estimation of pavement surface temperature and temperature distribution along layers is essential in pavement analysis and design for both flexible and rigid

\footnotetext{
${ }^{1}$ Civil Engineering Department, Sohag University, Sohag, Egypt (dr.talaat_ali@eng.sohag.edu.eg).

${ }^{2}$ Department of Civil Engineering, Ain Shams University, Cairo, Egypt; (m.elesawey@eng.asu.edu.eg).

${ }^{2}$ Mechanical Engineering Department, Sohag University, Sohag, Egypt; (sherif_hussien@eng.sohag.edu.eg).
} 
pavement [3]. In flexible pavement, the behavior of asphalt layers in response to traffic loads is dependent on the temperature profile of asphalt layers. This is caused by the change in viscoelastic behavior of asphalt, which occurs concurrently with temperature change [46]. Due to temperature variations, thermal fatigue damage may occur in a flexible asphalt layer [7-9]. The impact of air temperature and the temperature of pavement surface is mutual where the temperature of pavement surface is affected by weather characteristics and thermal properties of material layers while the air temperature is also affected by pavement surface temperature. These interactions are typically referred to as a microclimate system as illustrated in Figure 1 [10].

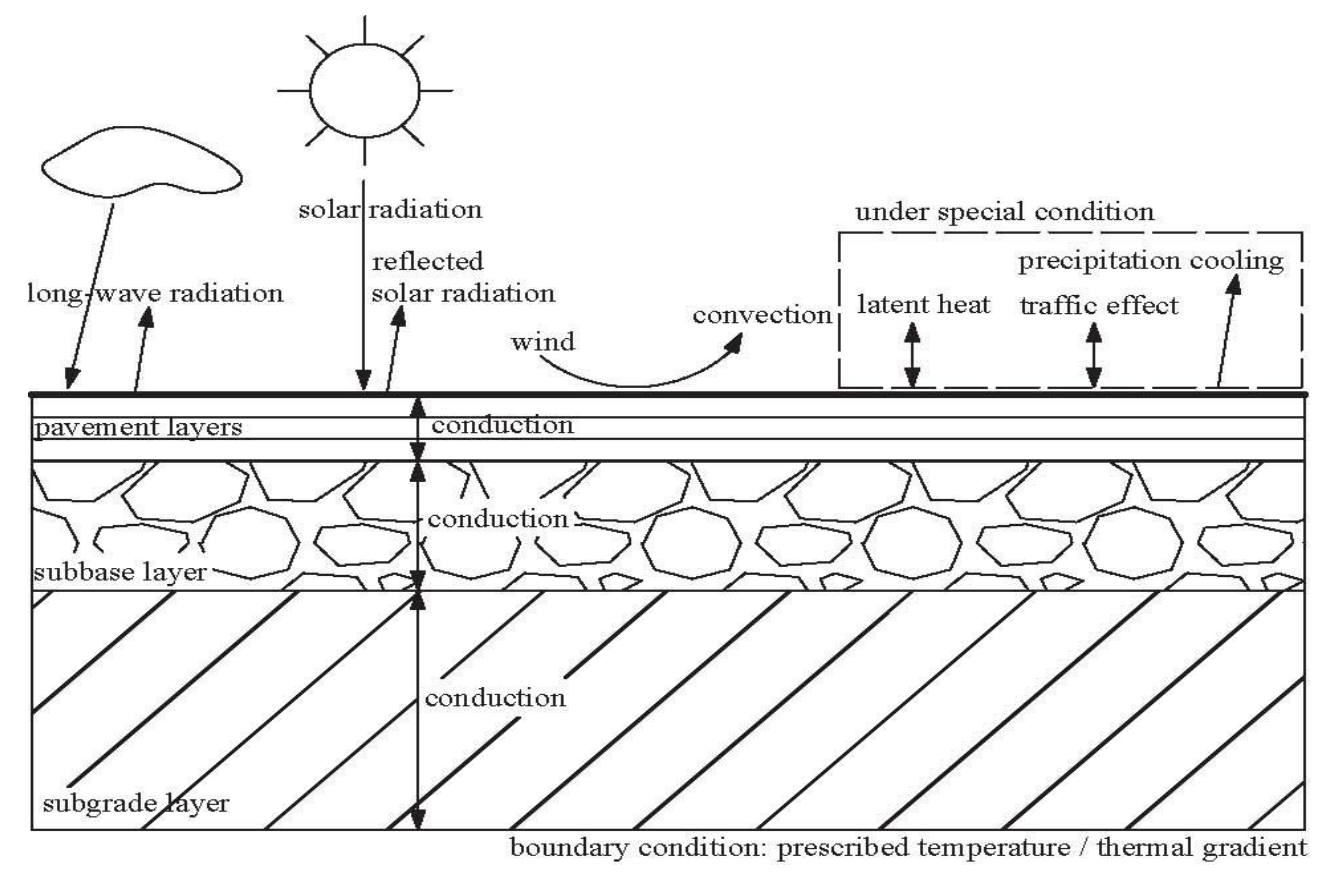

Fig 1. Microclimate system [10]

Pavement temperature has been used as an evaluation measure in some asphalt tests, such as the structural capacity or the remaining paving life using the falling weight deflectometer (FWD) test [11-13]. Recently, the amended Empirical Pavement Design Guide incorporated the effect of pavement temperature on material properties, pavement performance prediction, and structure responses [14]. Determining pavement surface temperature in cold regions, where roads are frequently covered by ice, is also an important factor in deciding on the time to conduct necessary maintenance [15-19]. The main objective of the research is to develop a mathematical model that is capable of estimating the temperature of pavement layers according to site location, time of the day, and day of the year. The suggested model considers the effect of solar flux on asphalt and the effect of heating and cooling of asphalt during daytime and nighttime. In this model, the effect of heat transfer by convection and radiation on the asphalt surface as a cooling process was incorporated.

\section{Previous Work}

Asphalt mixtures are viscoelastic plastic materials where the strength and modulus of elasticity change with substantial variation in temperature. Severe weather, especially high temperature, is one of the main factors that may lead to deterioration in flexible pavement 
layers. As a result, to meet structural and functional requirements, the asphalt mix design should be dependent on local temperature. Asphalt, for example, becomes hard and brittle in cold temperatures, exposing the asphalt layers to thermal and fatigue cracking. In high temperatures, however, asphalt becomes mushy and viscous, making it more prone to rutting.

Acknowledging its importance, reliable measurement of asphalt layers temperature has received considerable interest in the existing literature [20]. Different types of regression models were developed to determine the temperature either within asphalt pavement layers [Yavuzturk et al., 2005; Lukanen et al., 2000; and Khan et al., 2016] or at the surface pavement [Islam et al. (2015) and Diefenderfer et al. (2006)]. Most of these models are based on air temperature besides solar radiation and neglected other factors such as the effect of speed of wind and its direction and relative humidity. For example, Solaimanian and Kennedy [21] introduced an analytical model with maximum air temperature and solar radiation parameters to predict the maximum temperature of the pavement surface, as the pavement surface temperature attained equilibrium. Several other studies also developed analytical models to calculate pavement surface temperature [22-25]. The current model utilizes the energy balance equation and it adds the physical properties of the asphalt layers to solve the conduction energy equation for each layer. The mathematical model was solved for pavement layers simultaneously to calculate the temperature of each layer.

Linear and nonlinear regression were also used to determine maximum and minimum pavement temperature through a pavement layer [7,26]. Nonetheless, the approach is not deemed accurate due to the nonlinearity of pavement temperature throughout daytime. Islam (2015) and Asefzadeh et al. (2017) used regression models in the two studies to calculate layers temperature where only solar radiation and air temperature that were considered. The model neglected both the effects of thermal properties of asphalt layers and weather conditions (i.e. wind direction and speed, and relative humidity) $[7,26]$. Recently, Khan et al., (2019) developed three linear regression models to calculate asphalt surface temperature for daytime, 24- hour, and night-time to account for the change in weather conditions, especially in cold regions. The models included variables such as air temperature, wind direction and speed, solar radiation, and relative humidity. Despite the inclusion of weather variables, these models still suffer from the drawbacks of linear regression models. As well, the models did not take into account the effect of thermal properties of asphalt layers in addition to emissivity and surface albedo [27]. Adwan et al. (2022) investigated new models to predict the pavement temperature at specific depth, time, and air temprerture. The suggested models depended on 7200 measured pavement tempreture at four seasons (i.e. summer, winter, spring, and autumn, respectively)[28] Then, these models were validated usind data from field for one year. In later study, Adwan et al. (2022) used artificial neural networks (ANN) to predict also pavement temperature profile. The new study compared between the recent obtained results and results from previous models. It showed that the temperature predictions made by ANN were more accurate than those made by regression models $[29,30]$

An early numerical model to calculate asphalt surface temperature was introduced by Dempsey and Thompson, (1970) where the effect of weather conditions was considered [31]. Recently, the model was formerly referred to as Mechanistic-Empirical Pavement Design Guideline (MEPDG) and introduced as the first program to consider weather effect [32]. Several studies were conducted to predict pavement temperature based on finite element analysis [33-39] Many of these studies considered mainly the effect of thermal properties of pavement materials on surface temperature. Thermal conductivity, surface 
albedo, heat capacity, emissivity, and thermal disutility of pavement material were mostly expressed as thermal properties [40-47]. These properties can be gained directly from experiments or driven from previous studies [3]. The bearing capacity and the performance of flexible pavement are clearly affected by variation of modulus of asphalt mixture, which is significantly affected by pavement temperature.

In another similar context, the impact of temperature on bearing capability, performance, damage, and life of asphalt pavement was investigated [48,49]. Biswas et al. [50] investigated the seasonal variation of thermal-induced strain of flexible pavement. The results from field observation and laboratory tests showed that thermal strain is about 1.42.0 times greater than in warm seasons. Knowledge of regularities for temperature variation in time in pavement and subgrade are required.

In summary, the relationship between pavement surface temperature and weather conditions (e.g., solar energy, air temperature, air humidity, and wind speed) and thermal properties of asphalt layers including emissivity still needs further investigations, especially in hot regions.

\section{Methodology}

The cross-section shown in Figure 1 consists of a subgrade layer, sub-base layer, and pavement layers. The heat transfer between layers depends on the thermal conductivity and thermal properties of each layer. The surface layer is an absorber of solar radiation, and it is also open for heat transfer by convection and radiation. The solar energy is absorbed on the asphalt surface, transferred as conduction heat to the adjacent layer, and sequentially transferred to other layers. As well, the stored energy in the layers is transferred as convection heat to the ambient air and radiation heat to the sky from the upper surface. This model is mathematically expressed as simultaneous sets of system equations to calculate the temperature of each pavement layer. The model formulation along with its solution, are described in the following paragraphs.

\section{Model Formulation}

The analytical model described in this study has two main components: 1) energy balance and 2) solar energy determination.

\subsection{Energy Balance}

Environmental elements such as air temperature, sun radiation, asphalt surface radiation, and wind speed influence the temperature of the pavement surface. The main source of energy for pavements is short-wave radiation from the sun, and the percentage of sunshine is one factor used to calculate net short-wave radiation. Long-wave radiation emitted from the atmosphere, which is another heating source, is sometimes linked to air temperature. Parts of the input energy are lost due to convection and pavement sur-face radiation. The process of heat transfer through convection is linked to air temperature and wind speed. The pavement absorbs the rest of the energy and sends it to the lower layers. The temperature profile of the pavement is influenced by asphalt material qualities (e.g., surface short-wave absorption, heat capacity, and thermal conductivity).In the proposed model, pavement layers are considered thermal systems which receive solar energy and exchange 
the heat with the surrounding reservoir. The road section consists of asphalt, base, and subbase layers. Each layer is represented by one system of equations which are solved simultaneously such that [54]:

$$
\begin{aligned}
& \left(q_{s t}\right)_{a s p h}=\alpha_{a s p h} q_{s o l}-q_{r a d}-q_{c o v} \\
& \left(q_{s t}\right)_{b a s e}=q_{c o n 1}-q_{c o n 2} \\
& \left(q_{s t}\right)_{s u b b}=q_{c o n 2}-q_{c o n a}
\end{aligned}
$$

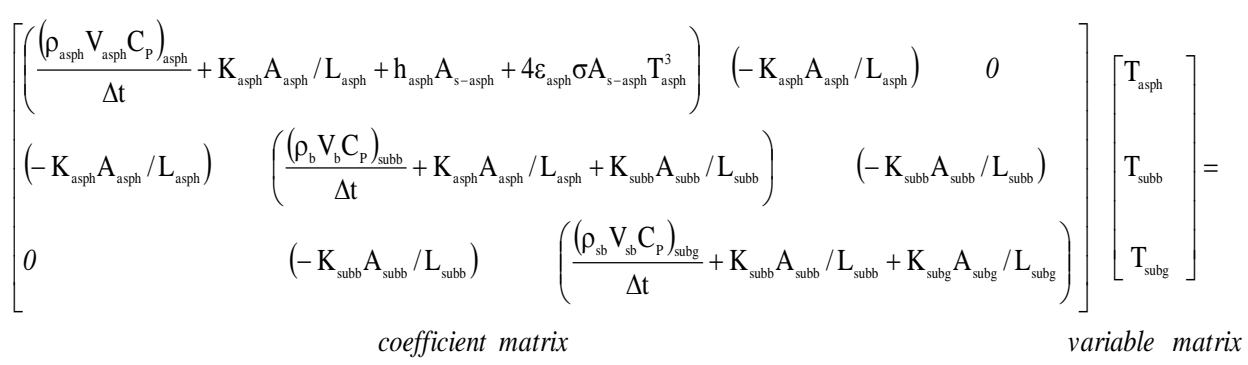

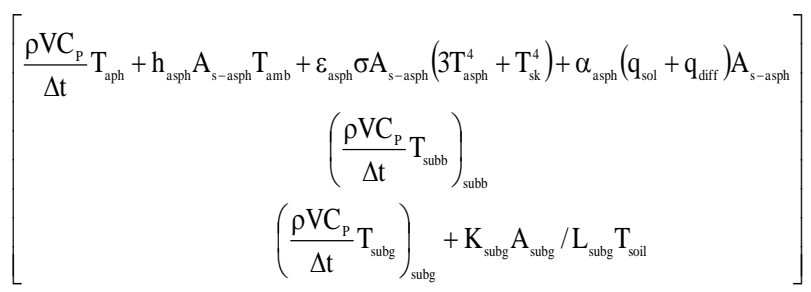

$$
\begin{aligned}
& \text { right hand side matrix }
\end{aligned}
$$

Equation (4) discretizes the set of systems of equations which shows the coefficient, variables and right-hand side matrices.

Where:

asph: asphalt

base: base

subb: sub-base

$q_{s t}:$ energy stored in a layer $\left(\mathrm{W} / \mathrm{m}^{2}\right)$

$q_{s o l}:$ total solar energy (beam and diffuse) incident on the pavement surface $\left(\mathrm{W} / \mathrm{m}^{2}\right)$

$\alpha_{\text {asph }}$ : asphalt surface absorptivity

$q_{\mathrm{rad}}$ : longwave radiation heat transfer from pavement surface to sky $\left(\mathrm{W} / \mathrm{m}^{2}\right)$

$q_{c o v}:$ convection heat transfer to/from pavement $\operatorname{surface}\left(\mathrm{W} / \mathrm{m}^{2}\right)$

$q_{c o n 1}$ : conduction heat transfer from asphalt to base $\left(\mathrm{W} / \mathrm{m}^{2}\right)$

$q_{\text {con } 2}$ : conduction heat transfer from base to sub-base $\left(\mathrm{W} / \mathrm{m}^{2}\right)$

$q_{\text {cona }}$ : conduction heat transfer from sub-base to sub-grade $\left(\mathrm{W} / \mathrm{m}^{2}\right)$

$\rho_{\text {asph }}$ : density of the asphalt material $\left(\mathrm{kg} / \mathrm{m}^{\mathrm{a}}\right)$

$\rho_{\mathrm{b}}$ : density of the base material $\left(\mathrm{kg} / \mathrm{m}^{\mathrm{a}}\right)$

$\rho_{\mathrm{sb}}$ : density of the sub-base material $\left(\mathrm{kg} / \mathrm{m}^{\mathrm{a}}\right)$

$C_{p}$ : specific heat of material layers (asphalt, base, sub-base) $\mathrm{kJ} / \mathrm{kg} . \mathrm{K}$

$\mathrm{V}_{\text {asph }}$ : specimen base volume $\left(m^{a}\right)$

$\mathrm{V}_{\mathrm{b}}$ : specimen base volume $\left(\mathrm{m}^{\mathrm{a}}\right)$ 
$\mathrm{V}_{\mathrm{sb}}$ : specimen sub-base volume $\left(\mathrm{m}^{\mathrm{a}}\right)$

$K_{\text {agph }}$ : asphalt thermal conductivity $(W / m . K)$

$K_{\text {base }}$ : base thermal conductivity $(W / m . K)$

$K_{\text {subb }}$ : sub-base thermal conductivity $(\mathrm{W} / \mathrm{m} . \mathrm{K})$

A: surface area of slab

$L_{\text {asph }}$ : asphalt layer thickness (m)

$L_{\text {base }}$ : base layer thickness (m)

$L_{s u b b}:$ sub-base layer thickness (m)

$h_{\text {asph }}$ : heat transfer coefficient from asphalt surface $\left(\mathrm{W} / \mathrm{m}^{2} \cdot \mathrm{K}\right)$

$T_{\text {asph }}$ : asphalt layer temperature $(\mathrm{K})$

$T_{\text {base }}$ : base layer temperature $(\mathrm{K})$

$T_{\text {subb }}$ : sub-base layer temperature $(\mathrm{K})$

$\sigma$ : Boltzmann constant $\left(W / m^{2} \cdot K^{4}\right)$

$\varepsilon$ : asphalt surface emissivity (-)

Solar Energy Determination

The clear sky solar energy model was used to calculate the solar beam radiation and the solar diffuse radiation [51].

$$
\begin{aligned}
& q_{s o l}=I_{b n} \cos \theta_{z}+I_{d} \\
& I_{b n}=A \exp \left(-B / \cos \theta_{z}\right) \\
& I_{d}=C I_{b n}
\end{aligned}
$$

Where:

$I_{b n}:$ direct normal beam

$I_{d}$ : diffuse irradiance

$\theta_{z}$ : solar zenith angle

A: apparent solar irradiance at air mass zero

B: atmospheric extinction coefficient

$\mathrm{C}$ : diffuse radiation factor

The values of $\mathrm{A}, \mathrm{B}$ and $\mathrm{C}$ vary with season and the atmospheric conditions.

Boundary Conditions

The problem is considered a one-dimensional heat transfer in the z-direction which is perpendicular to the pavement surface. This can be solved by modeling both convective heat transfer and radiation heat transfer.

Convective heat transfer consists of convection heat from dry air and convection heat from vapor of humid air in the atmosphere [54].

$$
\begin{aligned}
& q_{c o v-a}=h\left(T_{a g p h}-T_{a m b}\right) \\
& q_{c o v-D}=h_{m}\left(\rho_{V-a s p h} h_{V}-\rho_{V-a m b} h_{V}\right)
\end{aligned}
$$

Where:

$q_{c o v-\Omega}:$ convective heat transfer from dry air $\left(W / \mathrm{m}^{2}\right)$

$q_{c o v-V}:$ convective heat transfer from water vapor in the atmospheric humid air $\left(\mathrm{W} / \mathrm{m}^{2}\right)$ 


$$
\begin{aligned}
& \mathrm{h}=\left(5.7+3.8 \mathrm{C}_{\mathrm{w}}\right)_{\left(W / K \cdot m^{2}\right)}[51] \\
& c_{w}: \text { wind speed }(m / s) \\
& h_{m}=\left(18 h /\left(29 C_{p-a} x P_{a t m}\right)+3.8 C_{w}\right)_{(m / s)}[3]
\end{aligned}
$$

$C_{p-a}:$ air specific heat $(\mathrm{kJ} / \mathrm{kg} \cdot \mathrm{K}), P_{\operatorname{atm} m}$ is the atmospheric pressure $(\mathrm{kPa})$.

Radiation heat transfer, on the other hand, can be modeled as [46]:

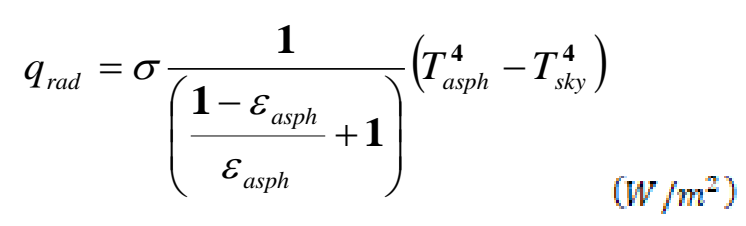

Where:

$\sigma$ : Stefan Boltzmann constant $\left(5.67 \times 10^{-8} \mathrm{~W} / \mathrm{m}^{2} K^{4}\right)$

$\varepsilon_{\text {asph }}$ : asphalt emissivity

\subsection{Model Implementation}

Figure 1 shows a typical cross-section consisting of three layers of asphalt, base and subbase. The proposed mathematical model is used to estimate the temperature of the three layers. The conduction heat transfer is the dominant phenomenon in layers thickness and the convection and radiation heat transfer phenomena were neglected inside the layers. The energy equations were solved simultaneously to estimate the temperature of each layer using the thermophysical properties of each layer. The equations were discretized to a numerical form to solve the mathematical model using an inverse matrix scheme in MATLAB. An implicit scheme [52] was chosen with a time step of $60 \mathrm{sec}$ which was checked to ensure no fluctuation in output data. Table 1 shows the thermal parameters used for each of the three layers.

Table 1. Thermal parameters of different layers

\begin{tabular}{lllc}
\hline Layer & $\mathrm{K}\left(\mathrm{W} / \mathrm{m}^{\circ} \mathrm{C}^{-1}\right)$ & $\mathrm{c}\left(\mathrm{kJ} / \mathrm{kg} /{ }^{\circ} \mathrm{C}\right)$ & $\rho\left(\mathrm{kg} / \mathrm{m}^{3}\right)$ \\
\hline Asphalt layer $^{1}$ & $1.8(1.5-2.0)$ & $0.9(0.9-1.3)$ & $2210(2297-2425)$ \\
\hline Base base $^{2}$ & $1.8(1.5-1.8)$ & $0.9(0.7-0.9)$ & $2210(1792-2405)$ \\
\hline Sub-base $^{\underline{3}}$ & $1.5(0.5-2.0)$ & $0.86(0.8-0.9)$ & $1560(1380-1600)$ \\
\hline
\end{tabular}

1 Ref. [53]

2 Ref. [54]

3 Ref. [55]

Where:

$\mathrm{k}\left(\mathrm{W} / \mathrm{m}^{\circ} \mathrm{C}^{-1}\right)$ : thermal conductivity of mediums.

$\rho\left(\mathrm{kg} / \mathrm{m}^{3}\right)$ : density of mediums.

c $\left(\mathrm{J} / \mathrm{kg} /{ }^{\circ} \mathrm{C}\right)$ : heat capacity of mediums; and

$\mathrm{q}\left(\mathrm{W} / \mathrm{m}^{-3}\right)$ : the internal heat generation rate 


\subsection{Model Validation}

\subsubsection{Pavement Surface Energy Balance}

The surface temperature of the pavement was measured using the installed devices and compared to the estimated surface temperature as obtained from the proposed model. As shown in Figure 2, the highest surface temperatures were recorded in summer months where the measured and the estimated temperatures were very close. Figure 3 shows the validation results for the sphalt concrete, base, and sub-base layers. The sub-base temperatures are almost the same, and there are no noticeable differences. This is due to the fact that the asphalt surface is subject to heat transfer by convection and radiation.
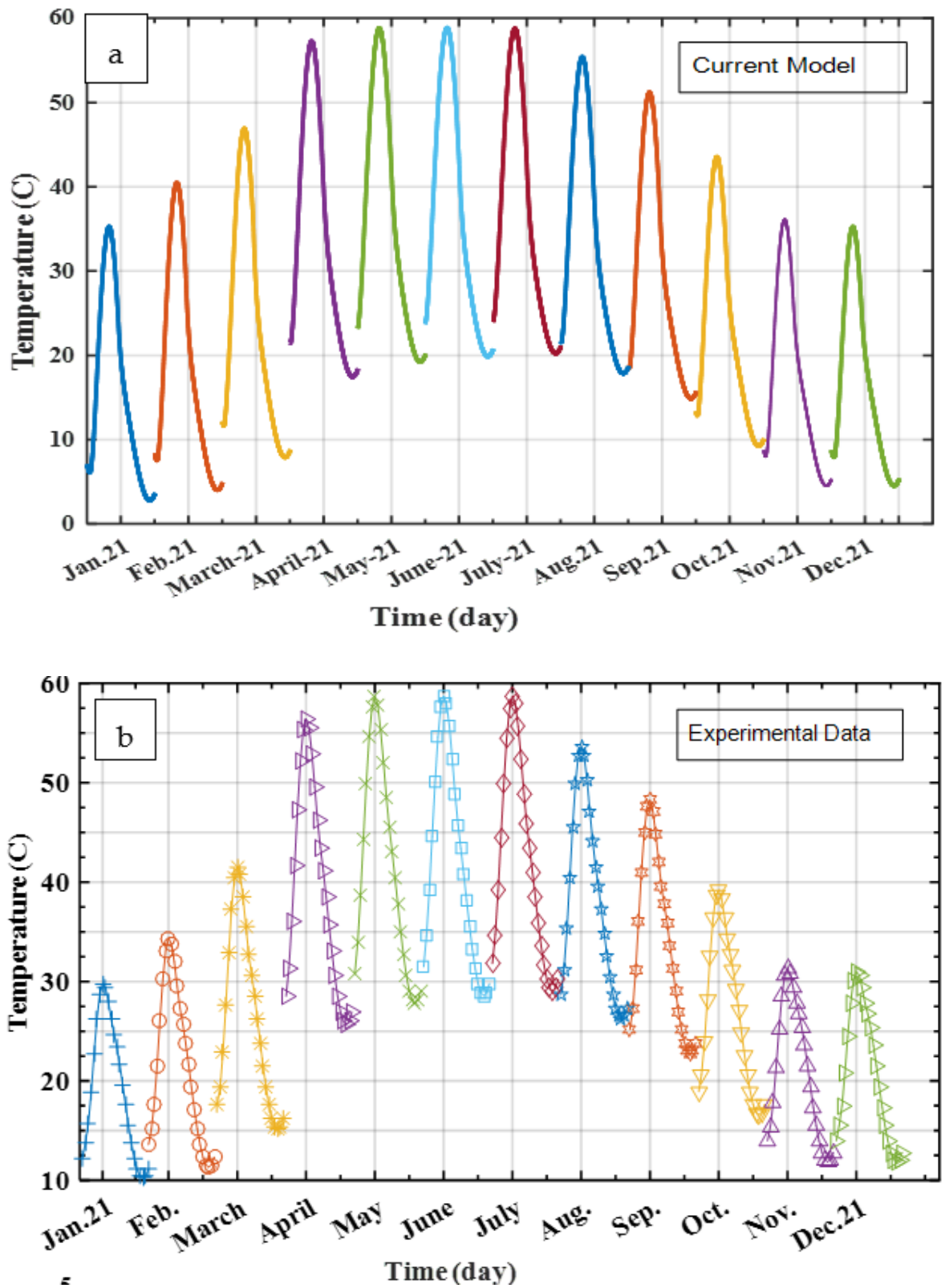

Fig 2. Validation of surface temperature between experimental data and current model 

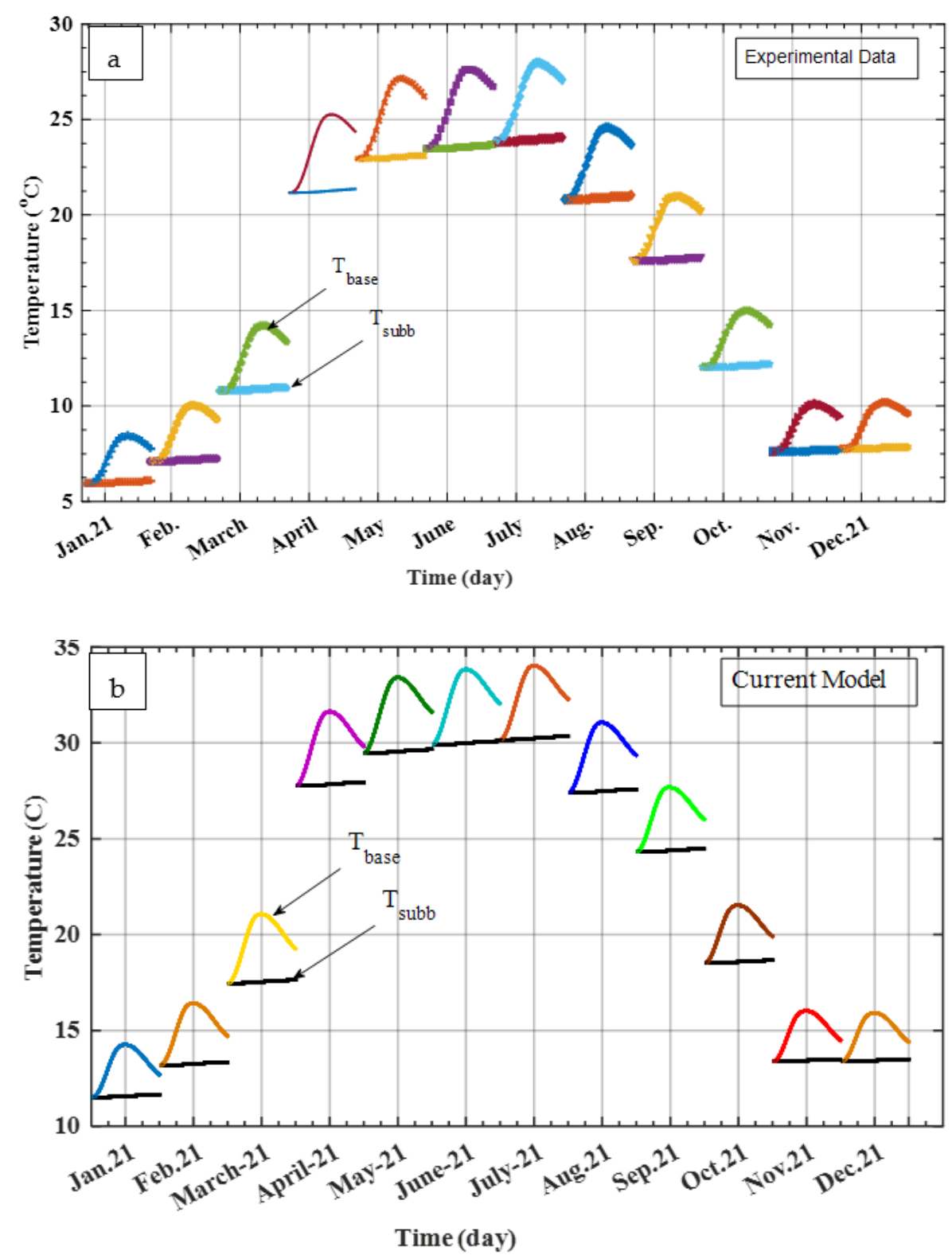

Fig 3. Validation of asphalt concrete, base, and sub-base temperatures for experimental data and the proposed model

The daily theoretical data for a day in March is shown in Figure 4. It depicts the ambient, surface, and layer temperatures, as well as convective, radiation, and solar beam and diffuse fluxes. At this time of day, convective heat transmission takes precedence over radiative heat transfer. At this time of day, radiative heat transmission takes precedence over convective heat transfer. From Figure 4 it is clear that the effect of heat transfer by convection was dominant over the effect of heat transfer by radiation. In addition to the high value of heat transfer by radiation as well. 

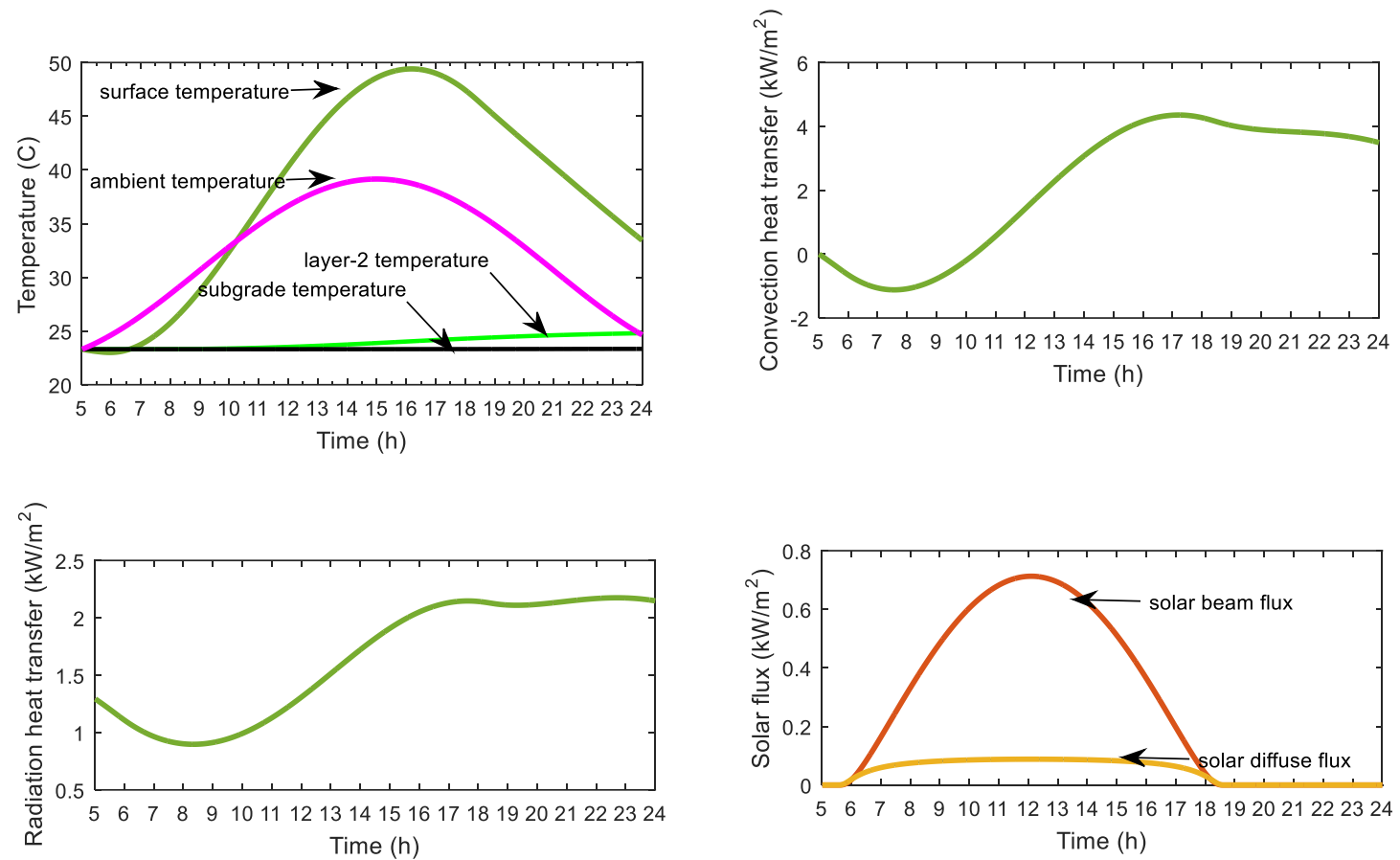

Fig 4. Daily theoretical data of March month for temperatures, convection heat transfer, radiation heat transfer, and solar flux

\subsubsection{Air and pavement surface temperature}

The temperature in highway subgrade points and the mean monthly air temperature were compared and found to be qualitatively same. As one might imagine, air temperature variation is the most important element in determining temperature variance in points of pavement and subgrade on a highway. As a result, air temperature variation must be analyzed in order to conduct detailed research on the highway's experimental section. The temperature of the pavement is influenced by the energy balance, particularly on the surface. The pavement absorbs heat from the sun at a roughly consistent rate throughout its service life (usually 20-40 years).The albedo (reflection coefficient) of a pavement surface is important in absorbing solar radiation, and it can have a big impact on the maximum pavement temperature. Radiation and convection both lose energy from the pavement, and the magnitude of convective heat loss is affected by air temperature and wind speed. Heat is transferred from the top layers of asphalt to the layers below. The temperature profile of the pavement is determined by the heat capacity and thermal conductivity of the paving components. The re-emission of previously absorbed heat by paved areas, via convection or radiation, is a significant component to the urban heat island effect; thus, albedo and the thermal properties of pavement materials are themselves indirect factors to local warming. In extreme circumstances, when the temperature rises dramatically on a daily/hourly basis, permanent deformation can develop quickly. Increases in temperature ranges as a result of climate change are likely to increase thermal stresses in asphalt layers, resulting in greater thermal cracking. Furthermore, greater temperatures can cause asphalt mixtures to age faster, and pavements can become more brittle, making them more prone to breaking.4.6. comparison to previous models

The proposed model was verified with the 24- hour model presented by Khan et al (2019) as in Figure 5. There is general consistency in the maximum temperature values for the months of January to February and March and October to December. As for the months of April to September, there is a more substantial difference in the maximum temperature values. For the minimum values of temperature, it was found that there is a noticeable difference 
between the proposed mathematical model and the 24- hour model. This is mainly attributed to the fact that the proposed model takes into consideration the heat transfer by convection and radiation, where this effect becomes more evident with the absence of sunlight and night cooling. In general, in the proposed model, heat storage is accounted for, which is important in studying thermal stress in a realistic manner. According to the heat transfer by radiation, convection, in addition to thermal storage, the difference between the minimum values of temperatures between the current model and the 24- model was found between 10 and $15^{\circ} \mathrm{C}$ (we can leave the numbers and add percentages too!). It is clear from the comparison between the model-24 and the current model that the current model has actually taken the effect of the sun's rays according to the actual real location, as well as the angles of the sun with the longitude and latitude of the exact location.

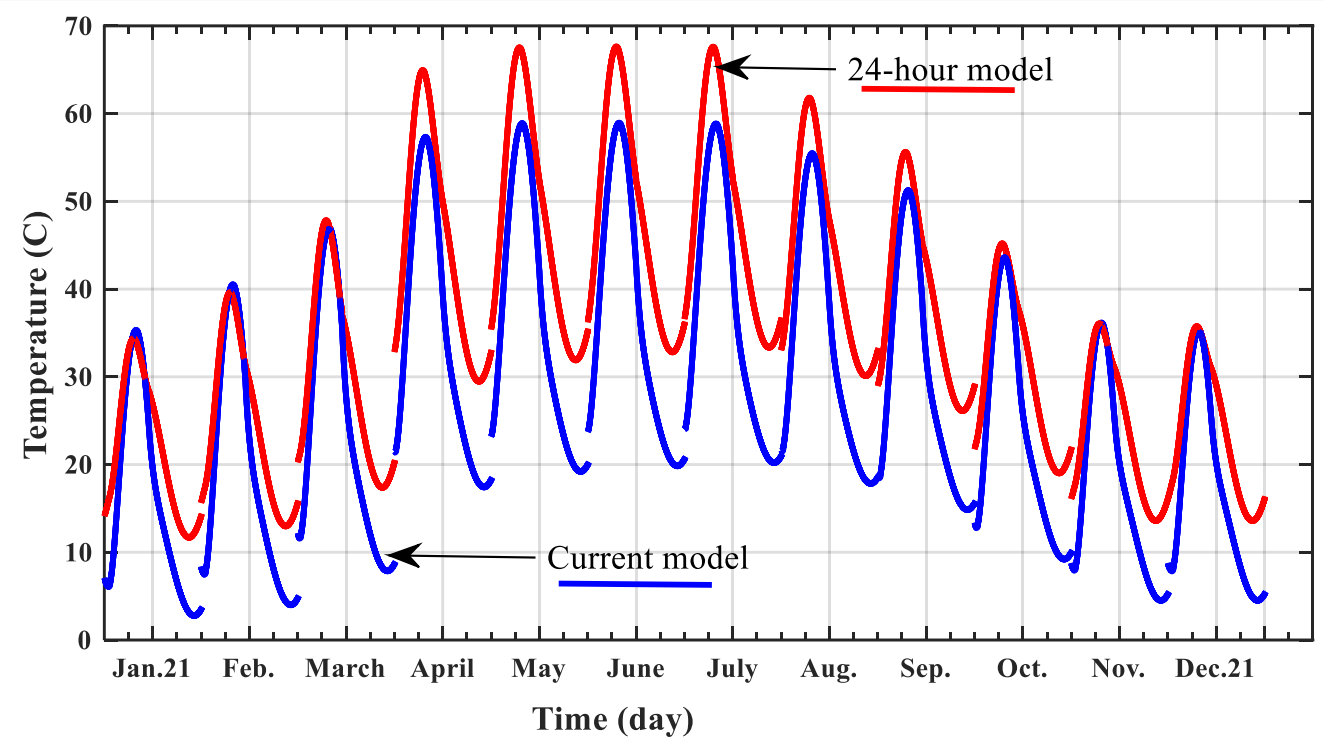

Fig 5. Verification of current model with 24- hour model for year's months

\section{Results}

To validate the proposed model, a case study is presented using the data collected over a year at an instrumented pavement section of a desert rural 2-lane 2-way highway in New Sohag, Egypt. The pavement section consists of three layers, subbase, base, and asphalt. All the experimental tests were carried out during daytime, good weather conditions and good road surface conditions. The following devices were installed on the road section to collect the data needed to validate the model:

A pyranometer is an actinometer that measures sun irradiation on a flat surface. Within a wavelength range of $0.3 \mu \mathrm{m}$ to $3 \mu \mathrm{m}$, the gadget detects the solar radiation flux density $(\mathrm{W} / \mathrm{m} 2)$ from the hemisphere above.

A thermocouple is a temperature sensor made composed of two dissimilar electrical wires that form electrical connections at different temperatures. Because of the thermoelectric effect, a thermocouple creates a temperature-dependent voltage, which may be used to monitor temperature.

Thermometers are devices that are attached to a thermocouple and are used to read the temperature the thermocouple detects. Wind Anemometer: a device used to measure the wind speed. 
A hygrometer: an instrument used to measure the amount of humidity and water vapor in the atmosphere.

One observation was recorded every hour for a whole day (i.e., 24 observations) for each month in 2020. Noteworthy is that the temperature of base and sub-base layers could only be measured by drilling multiple holes in the pavement section to capture the temperature gradient. This approach is time-consuming and deemed impractical. A more practical approach is to estimate the temperature of base and sub-base layers on correlation with measurable variables. This method is superior, since it is the only way to get design estimates for pavements that haven't been built yet [56]. To estimate pavement temperatures using weather data, several approaches and correlations have been devised. Some are based on heat-flow theory and calibrated with field data, while others are entirely based on actual data. Many of the established correlations are based on localized data, and their applicability in other meteorological circumstances is debatable. As previously stated, the temperature of the base and sub-base layers can be estimated using the correlation with observable factors. This method is preferred, as it is the only way to get design temperature estimates for pavements that haven't been built yet.

\section{Conclusions}

The current model was able to calculate the temperatures better because it depends on the angles of the sun and the longitude and latitude of the place. And also, the solution of the equations was by the direct method using the implicit solution of the inverse matrix. And this gives the least error of the indirect methods that depend on the assumption and repeated attempts to solve. The model took into account the thermal energy stored in the material as well as the night cooling, and all this helped in the more accurate calculations of the temperature, which is close to the temperatures taken by experimental measurements. Flexible pavement and weather are interactive. Pavement layers are weather-sensitive infrastructure elements, where the weather can impact their deterioration rate, subsequent maintenance, and life-cycle costs. In this paper, a couple heat transfer model was developed to estimate flexible pavement surface and layers temperatures considering weather and pavement parameters from one year. The model was implemented in MATLAB, and the results were generally consistent with experimental data. The proposed model is vital in highway's design and analysis because the increase in temperature tends to accelerate pavement deterioration. The proposed model has an advantage over empirical equations as it considers the heat storage and heat transfer by convection, radiation, and night cooling. All these factors have an effect on thermal stress and therefore they should be included in any temperature estimation model. The radiative heat transfer is the main factor for cooling asphalt layers until it becomes approximately equal in temperature to the subgrade. Intuitively, the higher the temperature, the worse the deterioration, and accordingly the more significant reduction in service life of the pavement. This necessitates earlier intervention strategies and a significant budget increase for road maintenance. High temperature is the most influential weather factor on flexible pavement, and its impact can accumulate over the complete service life. Pavement design methods should consider global warming which leads to the unexpected higher temperature in the future. Although it is possible to upgrade asphalt binder to adapt to higher temperatures, its cost-effectiveness is debatable. As a result of climate change, important road networks will require pavement 
care sooner. Road organizations must be aware of this and be prepared for repair money to arrive considerably early.

Funding: There was no outside support for this study. Informed Consent Statement: Not applicable.

Conflicts of Interest: There are no conflicts of interest declared by the authors

\section{References}

[1] A. Ongel, J. Harvey, Analysis of 30 years of pavement temperatures using the enhanced integrated climate model (EICM), Pavement Res. Cent. (2004).

[2] C.E. Zapata, D. Andrei, M.W. Witczak, W.N. Houston, Incorporation of environmental effects in pavement design, Road Mater. Pavement Des. 8 (2007) 667-693.

[3] J. Chen, H. Wang, P. Xie, Pavement temperature prediction: Theoretical models and critical affecting factors, Appl. Therm. Eng. 158 (2019) 113755.

[4] J. Chen, H. Wang, M. Li, L. Li, Evaluation of pavement responses and performance with thermal modified asphalt mixture, Mater. Des. 111 (2016) 88-97.

[5] H. Wang, I.L. Al-Qadi, Importance of nonlinear anisotropic modeling of granular base for predicting maximum viscoelastic pavement responses under moving vehicular loading, J. Eng. Mech. 139 (2013) 29-38.

[6] I.L. Al-Qadi, H. Wang, Prediction of tire pavement contact stresses and analysis of asphalt pavement responses: A decoupled approach, Asph. Paving Technol. Assoc. Asph. Technol. 80 (2011) 289.

[7] M. Islam, Thermal Fatigue Damage of Asphalt Pavement. University of New Mexico, Albuquerque, (2015).

[8] Z. Khan, H.M. Faisal, R. Tarefder, Fracture toughness measurement of asphalt concrete by nanoindentation, in: ASME Int. Mech. Eng. Congr. Expo., American Society of Mechanical Engineers, 2017: p. V010T13A010.

[9] M.R. Islam, S. Ahsan, R.A. Tarefder, Modeling temperature profile of hot-mix asphalt in flexible pavement, Int. J. Pavement Res. Technol. 8 (2015) 47.

[10] D. Annaratone, Engineering heat transfer, Springer Berlin Heidelberg, 2010. https://doi.org/10.1007/978-3-642-03932-4.

[11] E.O. Lukanen, R. Stubstad, R.C. Briggs, B. Intertec, Temperature predictions and adjustment factors for asphalt pavement, Turner-Fairbank Highway Research Center, 2000.

[12] D.-H. Chen, J. Bilyeu, H.-H. Lin, M. Murphy, Temperature correction on falling weight deflectometer measurements, Transp. Res. Rec. 1716 (2000) 30-39.

[13] M. Li, H. Wang, G. Xu, P. Xie, Finite element modeling and parametric analysis of viscoelastic and nonlinear pavement responses under dynamic FWD loading, Constr. Build. Mater. 141 (2017) 23-35.

[14] Aa. AASHTO, Mechanistic-empirical pavement design guide: A manual of practice, AAoSHaT Off. Ed. (2008).

[15] A.D.W. Nuijten, Runway temperature prediction, a case study for Oslo Airport, Norway, Cold Reg. Sci. Technol. 125 (2016) 72-84.

[16] M. Kangas, M. Heikinheimo, M. Hippi, RoadSurf: a modelling system for predicting road weather and road surface conditions, Meteorol. Appl. 22 (2015) 544-553.

[17] J. Shao, P.J. Lister, An automated nowcasting model of road surface temperature and state for winter road maintenance, J. Appl. Meteorol. 35 (1996) 1352-1361.

[18] L.-P. Crevier, Y. Delage, METRo: A new model for road-condition forecasting in Canada, J. Appl. Meteorol. 40 (2001) 2026-2037.

[19] B.H. Sass, A numerical model for prediction of road temperature and ice, J. Appl. Meteorol. 31 (1992) 1499-1506.

[20] R.H. Ramadhan, H.I.A.-A. Wahhab, Temperature variation of flexible and rigid pavements in Eastern Saudi Arabia, Build. Environ. 32 (1997) 367-373.

[21] M. Solaimanian, T.W. Kennedy, predicting maximum pavement surface temperature using maximum air temperature and hourly solar radiation, Transp. Res. Rec. (1993) 1.

[22] A. Hermansson, Simulation model for calculating pavement temperatures including maximum 
temperature, Transp. Res. Rec. 1699 (2000) 134-141.

[23] D. Wang, simplified analytical approach to predicting asphalt pavement temperature, J. Mater. Civ. Eng. 27 (2015) 4015043.

[24] D. Wang, Prediction of time-dependent temperature distribution within the pavement surface layer during FWD testing, J. Transp. Eng. 142 (2016) 6016002.

[25] J. Chen, H. Wang, H. Zhu, Chen et al., 2017], Appl. Therm. Eng. 113 (2017) 739-748.

[26] A. Asefzadeh, L. Hashemian, A. Bayat, Development of statistical temperature prediction models for a test road in Edmonton, Alberta, Canada, Int. J. Pavement Res. Technol. 10 (2017) 369-382.

[27] Z.H. Khan, M.R. Islam, R.A. Tarefder, Determining asphalt surface temperature using weather parameters, J. Traffic Transp. Eng. (English Ed. 6 (2019) 577-588.

[28] H.F. Hassan, A.S. Al-Nuaimi, R. Taha, T.M.A. Jafar, Development of asphalt pavement temperature models for Oman, J. Eng. Res. [TJER]. 2 (2005) 32-42.

[29] I. ADWAN, A. MILAD, N.H. ABDULLAH, I. WIDYATMOKO, M. MUBARAKI, M.R.M.A.T. YAZID, N.U.R.I.M.D. YUSOFF, PREDICTING ASPHALT PAVEMENT TEMPERATURE BY USING NEURAL NETWORK AND MULTIPLE LINEAR REGRESSION APPROACH IN THE EASTERN MEDITERRANEAN REGION, (n.d.).

[30] G.S. Moussa, M. Owais, Modeling Hot-Mix asphalt dynamic modulus using deep residual neural Networks: Parametric and sensitivity analysis study, Constr. Build. Mater. 294 (2021) 123589.

[31] B.J. Dempsey, M.R. Thompson, A heat transfer model for evaluating frost action and temperaturerelated effects in multilayered pavement systems, Highw. Res. Rec. (1970).

[32] Q. Li, D.X. Xiao, K.C.P. Wang, K.D. Hall, Y. Qiu, Mechanistic-empirical Pavement Design Guide (MEPDG): a bird's-eye view, J. Mod. Transp. 19 (2011) 114-133.

[33] G.S. Moussa, M. Owais, Pre-trained deep learning for hot-mix asphalt dynamic modulus prediction with laboratory effort reduction, Constr. Build. Mater. 265 (2020) 120239.

[34] T. Abdel-Wahed, H. Al Nageim, Investigating the effects of cement and cement kiln dust as a filler on the mechanical properties of cold bituminous emulsion mixtures, Int. J. Civ. Eng. Technol. 7 (2016) 441-453.

[35] B.B. Teltayev, K. Aitbayev, Modeling of transient temperature distribution in multilayer asphalt pavement, Geomech. Eng. 8 (2015) 133-152.

[36] R.B. Mallick, B.-L. Chen, A. Veeraragavan, G.L. Babu, S. Bhowinick, Reduction of Pavement High Temperature with the Use of Thermal Insulation Layer and High Reflectivity Surface., Int. J. Pavement Res. Technol. 7 (2014).

[37] B.A. Young, G. Falzone, Z. She, A.M. Thiele, Z. Wei, N. Neithalath, G. Sant, L. Pilon, Early-age temperature evolutions in concrete pavements containing microencapsulated phase change materials, Constr. Build. Mater. 147 (2017) 466-477.

[38] D. Yinfei, H. Zheng, C. Jiaqi, L. Weizheng, A novel strategy of inducing solar absorption and accelerating heat release for cooling asphalt pavement, Sol. Energy. 159 (2018) 125-133.

[39] T.A. Abdel-Wahed, N.K. Rashwan, Application of Cement Dust and OPC as Mineral Filler in the binder Hot Mix Asphalt, Eng. Infrastruct. 15 (2016).

[40] J. Gui, P.E. Phelan, K.E. Kaloush, J.S. Golden, Impact of pavement thermophysical properties on surface temperatures, J. Mater. Civ. Eng. 19 (2007) 683-690.

[41] W. Sheng Yue, Z. QiYang, D. YingNa, S. PeiDong, Unidirectional heat-transfer asphalt pavement for mitigating the urban heat island effect, J. Mater. Civ. Eng. 26 (2014) 812-821.

[42] J. Chen, H. Wang, H. Zhu, Analytical approach for evaluating temperature field of thermal modified asphalt pavement and urban heat island effect, Appl. Therm. Eng. 113 (2017) 739-748.

[43] J. Yang, Z.-H. Wang, K.E. Kaloush, H. Dylla, Effect of pavement thermal properties on mitigating urban heat islands: A multi-scale modeling case study in Phoenix, Build. Environ. 108 (2016) 110121.

[44] D. Feng, J. Yi, D. Wang, Performance and thermal evaluation of incorporating waste ceramic aggregates in wearing layer of asphalt pavement, J. Mater. Civ. Eng. 25 (2013) 857-863.

[45] P.K. Dehdezi, R.M. Hall, A. Dawson, Thermo-Physical Optimisation of Specialized Concrete Pavement Materials for Surface Heat Energy Collection and Shallow Heat Storage Applications, (2011).

[46] H. Wu, B. Sun, Z. Li, J. Yu, Characterizing thermal behaviors of various pavement materials and their thermal impacts on ambient environment, J. Clean. Prod. 172 (2018) 1358-1367.

[47] H. Li, J. Harvey, D. Jones, Multi-dimensional transient temperature simulation and back-calculation for thermal properties of building materials, Build. Environ. 59 (2013) 501-516. 
[48] H.-G. Kang, Y. ZHENG, Y. CAI, Y. LIU, Regression Analysis of Actual Measurement of Temperature Field Distribution Rules of Asphalt Pavement [J], China J. Highw. Transp. 6 (2007).

[49] L. Wei, S. Kayser, F. Wellner, Impact of surface temperature on fatigue damage in asphalt pavement, J. Highw. Transp. Res. Dev. (English Ed. 7 (2013) 1-6.

[50] S. Biswas, L. Hashemian, A. Bayat, Investigation on seasonal variation of thermal-induced strain in flexible pavements based on field and laboratory measurements, Int. J. Pavement Res. Technol. 9 (2016) 354-362.

[51] M.M. Elsayed, Parametric study of a direct solar-operated, multiple-effect, diffusion still, Sol. Wind Technol. 3 (1986) 95-101.

[52] S. V Patankar, Numerical heat transfer and fluid flow (Book), Washington, DC, Hemisph. Publ. Corp., 1980. 210 P. (1980).

[53] J. Luca, D. Mrawira, New measurement of thermal properties of superpave asphalt concrete, J. Mater. Civ. Eng. 17 (2005) 72-79.

[54] J. Côté, J.-M. Konrad, Thermal conductivity of base-course materials, Can. Geotech. J. 42 (2005) 6178.

[55] S. Lu, T. Ren, Y. Gong, R. Horton, an improved model for predicting soil thermal conductivity from water content at room temperature, Soil Sci. Soc. Am. J. 71 (2007) 8-14.

[56] C. Marshall, R. Meier, M. Welch, Seasonal temperature effects on flexible pavements in Tennessee, Transp. Res. Rec. 1764 (2001) 89-96. 


\section{تطوير وتقيمي نموذج مثزامن لتقدير درجة حرارة طبقات الرصف}

التخاضيص:

تتعرض العديد من الطرق في المناطق الحارة من العالم لدرجات حرارة عالية جدًا خاصة في المناطق الصحر اوية خلال فصل الصيف حيث قد تصل درجة الحرارة أحيانا إلى أكثر من ستين درجة مئوية. وتتسبب التغيرات في درجات الحرارة في حدوث الكثير من العيوب في الرصف سوآها المرن أو الجاسئ منل التخدد، الثرخ المستعرض الر أسي (أب الثروخ الحرارية)، والكلل الناتج عن الإجهاد الحراري، الهبوط / الالتواء، بالإضافة إلى توليد ضغوط الاعوجاج. ويعد الحساب الدقيق لدرجة حر ارة سطح الرصف المرن مهمًا جدًا في تحليل وتصميم طبقات الرصف. يقدم هذا البحث نموذجًا رياضيا جديدًا لتقدير درجة حرارة طبقات الرصف المرنة تحت درجات حرارة عالية جدًا كمجموعة من المعادلات المتزامنة. تضمن النموذج المقترح Clear-Sky) كنموذج فرعي لحساب الطاقة الثمسية وانتشار الإشعاع الثمسي على سطح الأسفلت. تم حساب درجة الحرارة المحيطة من خلال حل النموذج الرياضي طو ال ساعات اليوم. تم التحقق من صحة النموذج المقترح من خلال القياسات لدرجات الحرارة والرطوبة النسبية وسر عه الرياح التي تم جمعها لمدة عام واحد باستخدام أجهزة قياس مثنتة بقطاعات الرصف بمدينه سوهاج الجديدة، مصر. تم قياس درجات حرارة سطح الأسفلت للاعندالات الصيفية و الثتوية والاعتدالات الربيعية والخريفية. وجد أن النموذج يقدم تقديرات مقبولة مقارنة بالبيانات المقاسة من الموقع. يعتبر النموذج المقترح مناسباً لتقدير درجة حرارة طبقات الرصف في المناطق المختلفة لتمكن النموذج الرياضي المقترح من الحل حسب الموقع الجغر افي للمكان خاصة المناطق الحارة منها. 